\title{
TRENDS IN BLOCKCHAIN AND NEWER TECHNOLOGIES USES IN LOGISTICS AND SUPPLY CHAIN MANAGEMENT
}

\author{
Ephrem Eyob,eeyob@vsu.edu \\ Simon Eyob, seyob99@vt.edu
}

\begin{abstract}
Modern logistics and supply chain management use customer relations management software (CRM) to manage customers, vendors, manufacturing, sales force marketing and demand estimates using mobile connected tools. The mobile phone and hand-held radio frequency identification (RFID) readers can connect with CRM system with virtually no delay to share data and information. These efficiencies bring complete and accurate information in real-time to make necessary transactions, inventory and manufacturing schedules status and adjustments. The latest trends of information technology that is impacting logistics and supply chain management are blockchain transaction processing, artificial intelligence (AI), internet of things (IoT), autonomous vehicles and drones, and advanced analytics. Selecting proper technology for logistics and supply chains operations or sub-processes is very critical for business enterprise to gain competitive advantage in today's competitive market. The paper will explore the impact of these new technologies with emphasis on blockchain potential to improve logistics and supply chain management to make these important sectors of the economy more efficient, effective and profitable.
\end{abstract}

Keywords: Logistics, Supply Chain, Blockchain, Internet of Things, Artificial Intelligence. Machine Learning, RFID

\section{INTRODUCTION}

In the evolution of information systems and communication technologies (ICT), the Internet has played a primary role in the explosive growth of information systems for logistics and supply chain applications (Kukier, 1999). Managing logistics and supply chain is a complex undertaking that may include material sourcing, production, distribution and flow of information supported through modern technologies (Ketikids et. al, 2008). Historically, logistics and supply chain management adopted technologies related to production planning early on. The first such technology was material requirement planning (MRP), added financing modules to MRP and renamed it as MRPII. Then followed enterprise resources planning (ERP), supplier relationship management (SRM), customer relationships management (CRM) and related technologies. Advances in technology is introducing cutting-edge technologies such as AI, RFID, Blockchain transactions, autonomous vehicle and drones for competitive advantage by organizations.

The constant reduction of costs of hardware, software, and operating costs have made voice over internet protocol (VoIP), internet protocol television (IPTV), videoconferencing, IP multimedia systems as technology of choice to many businesses including the logistics industry (Materna, 2006). Improvement in technology has contributed to major increase in productivity in logistics and supply chain. The innovations and advances have helped in niche areas of logistics and supply chains including fast transportation with accurate tracking and reporting. The paper will provide brief over-view on major innovative technology advances that are trending and influencing in the logistics and supply chain industry applications. The rest of the paper is organized as follows: Literature review, brief over-view applications of artificial intelligence, machine learning, internet of things, autonomous vehicle, advanced analytics, blockchain, and finally the conclusion. 


\section{LITERATURE REVIEW}

There is an increasing trend of digitization and automation with innovative disruptive transformation of supply chains and resulting in a change of product or service offering which impacts significantly how organizations manage their operations (Waller et, al, 2014; Berman, 2012; Hess, et. al, 2012; Hoffman, et. al, 2017; and Fitzgerald, et. al., 2014). For many decades public switched telephone network (PSTN) has played the role as the backbone for reliable communication technology for many organizations including logistics and supply chain. However, PSTN is now a matured declining technology with the advent of cellular telephony and VoIP. VoIP as a growth technology has not yet attained the technological maturity in terms of quality, security, and compatibility compared to PSTN. VoIP's infrastructure is based on the Internet and is vulnerable to security threats. In addition to the above technologies in logistics and supply chain, newer innovative technology such as blockchain, autonomous vehicles, artificial intelligence and other similar technology are being implemented in service sectors such as logistics and supply chain management.

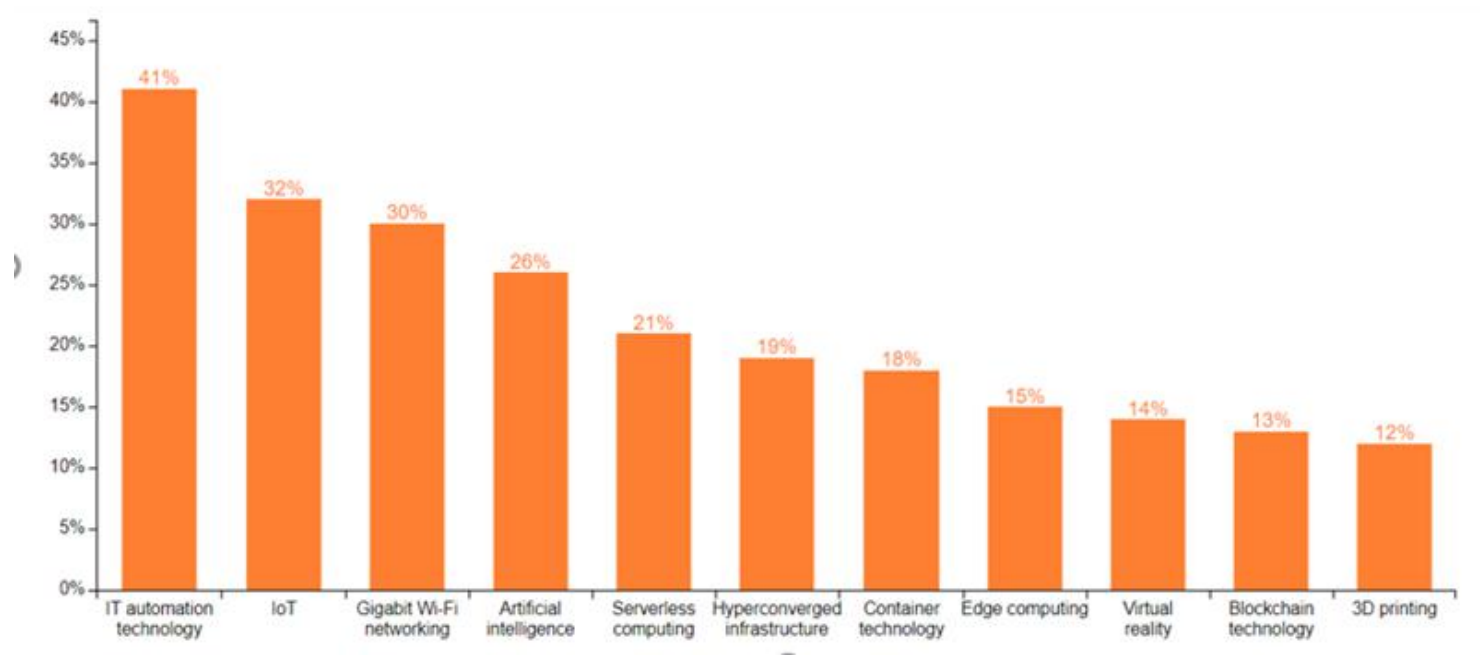

Figure 1. Technology trends expected with biggest impact

To business in 2018

Adapted from Spiceworks.com (2018)

Figure 1 shows technology trends with expected impact to business in 2018 with automation, IoT, gigabit Wi-Fi network, and artificial intelligence leading the pack (State of IT, 2019). Advanced technologies such as blockchain transactions, artificial intelligence (AI), automated robotics (AR), RFID, global positioning satellites (GPS) and wireless mobile technology have brought great innovations in logistics and supply chain management with mixed results in some instances. Blockchain based on the State of IT survey was rated only $13 \%$ as it is viewed as not ready for wide applications and implementation-more work needs to be done in blockchain technology to scale it and gain acceptance. Ketikids (2008) argues, "although cases of better tracking of product logistics, improved efficiency in information processing, improved security, reduced counterfeit, fast-tracked quotation and ordering, improved customer relationships, better control supply have been reported." Invariably, most of the applications of these advanced technologies are in developed countries as they require advanced infrastructure in transportation, telecommunication and electric power generations.

Wireless cellular telephony with text, video, and voice features is spreading all over the world including developing countries and is being adapted quickly because of the cost and strategic advantages in quickly putting these infrastructures as compared to old online cable-based connections of PSTN. 5G network is 100 times faster than 4G and are being installed in many countries of the world which will impact positively both logistics and supply chains operations. Internet based voice applications are becoming a strategic competitive tools in being integrated for electronic commerce such as business to business (B2B), business to commerce (B2C), business to government (B2G), customer relations management (CRM), and logistics applications with features of converting voice into text and text to voice (Turban, 2006). These types of systems are useful in supporting logistics and supply chain or for that matter any digital information as they are searchable easily for textbased information. Artificial intelligence technology for logistics with advanced features help logistics operations and related 


\title{
Issues in Information Systems
}

\author{
Volume 20, Issue 2, pp. 47-55, 2019
}

applications to integrate important features that make the system more effective and can add language translations capacity that include global related logistics when the language of operations is different. Intelligent Multimedia Knowledge Application (IMKA) represents the effort to search knowledge from multimedia contents in voice, video, static pictures, and text (Benitez, 2004). It is a promising area that can advance the formation of knowledge and help business run their operations efficiently. The rest of the paper will cover the newest technologies with emphasis on blockchain to help logistics and supply chains to be more efficient and effective to reduce cost and improve services.

Artificial Intelligence (AI) technology is an important tool in service management as organizations seek to become more efficient and find ways to avoid repetitive tasks (Zach, 2018). Artificial Intelligence is the application of computers to imitate human tasks. Deep learning is the theory that computers can achieve the performance of humans to complete tasks fasters and accurately. Deep learning applications are widely used in logistics and supply management application in visual perception, speech recognition, decision making, warehousing, shipment, and inventory management (Simon, et.,al 2016).

Vadnais (2015) argued enhanced artificial intelligence (AI) approach can help the decision-making process for the logistics management. The purpose of artificial intelligence is to understand how different facts are interconnected to form knowledge and to represent that knowledge in a machine-understandable form (Whiston, 2018). Reasoning and learning are the next steps of IA after knowledge representation. Advances in machine learning, deep learning and artificial intelligence (AI) are being implemented in logistics and supply chain management (McCrea, 2018). From autonomous robots equipped with AI that work on the dock to drones that manage the assembly plant and automate the inventory to sensors that track shipment condition during transport is the next wave of innovations with expected investment in the tens of billions of dollars.

Machine Learning (ML) is data analysis technique that automates analytical model building by identifying, detecting, categorizing, and prediction of data (Nevala, 2019). It is a sub-field of artificial intelligence (AI) foundation that systems can self-learn from data, identify patterns and make prediction and decisions with minimal human intervention (Nevala, 2017). The McKinsey Global Institute predicts machine learning will be the most sought innovation in the near future (Manyaka, et al., 2011). Deep learning is a method to learn multi-layer of information using artificial neural network (ANN) that requires relatively little data (Simon, et al, 2016). Machine learning is currently applied in self driving cars, online recommendation for multitude uses in everyday life, automated data mining in social media and learn what customers wants and thinking by using linguistic rule based exploration, image and text detection, and finally fraud detection for credit card uses and other transactions. Many applications mentioned are embedded in logistics and supply chains applications and have great promise to solve problems that are not conducive to analyze using traditional analytical techniques. Figure 1 shows the likelihood of impact to people by the new technologies such autonomous weapons, autonomous vehicles, AI failures, surveillance and data privacy according to a survey conducted by US Public Report (2019). Although machine learning is an important technology for many applications, the biases embedded in the algorithms are some of the major concerns as they may cause harm that need to be studied and remedied before wide use in everyday life including logistics and supply chains are adopted.

Internet of Things (IoT) many modern devices are made with embedded Wi-Fi capabilities and sensors. These devices send signals and are inter-connect by sending and receiving data. IoT has many uses in logistics and supply chain to conduct inventory audit, process accounting on the fly, reduce operations costs and risks. It is predicted the number of IoT to reach 20 billion in 2020 (Hung, 2017). Sensors can be embedded in most anything from human beings, animals, cars and trucks, trains, cargo ships and airplanes and can transmit data to a centralized system to conduct analysis and gain insights about the object or process in question. IoT's innovations continue to break new ground by impacting the future of supply chain and logistics by improving delivery of goods and service and have more accurate visibility of the processes. According to an article (How Technology is changing the Future of Logistics, 2019), RFID chip or tags can save labor costs and can track inventory. Commonly, tags are placed on the product and send radio signals to be processed for warehouse distribution to monitor items. Figure 2 shows a conceptual framework of anytime-anything-anyplace connection (Goudos, et.al 2017). The connection could be from any things any time any place on the move, outdoor, indoor, night, daytime between PCs, human to human, thing to thing, human to pc, human not using pc etc. IoT and Internet of Bodies IoB (IEEE, 2019) are finding applications even inside the human bodies. Self-tracking applications for consumers, for example, fitness and smart glasses, digital pills, embedded IoB can interact with sensors to collect real time data for better decision making. These multitude of applications can provide better and faster information for decision making; however, their uses raises major privacy, security, and abuse issues by the implementors of these exciting technologies. IoT applications have uses beyond smartphones and tablet that can run on the cloud. Many believe advanced technology will replace IoT in the near future that will be ubiquitous in every day operations of companies and homes. As IoT applications become ubiquitous in logistics and supply chains, the issues of privacy, and security 


\section{Issues in Information Systems}

Volume 20, Issue 2, pp. 47-55, 2019

become utmost important in the operations of business and organization. Currently, many researchers are prodding these fertile area of investigations.

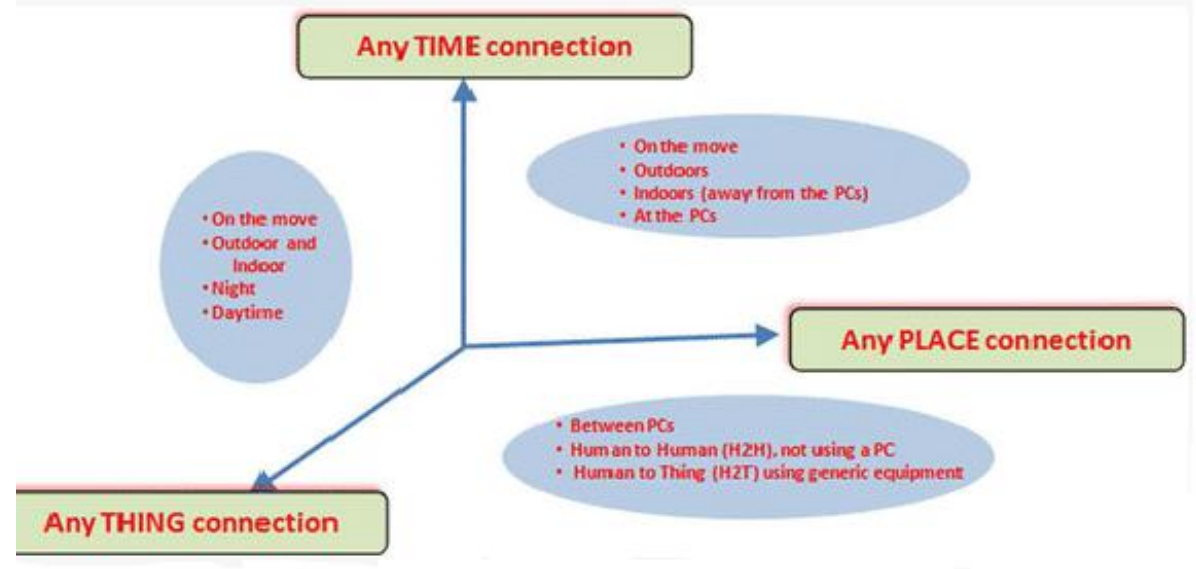

Figure 2. IoT Connectivity Framework

Source: Goudos, et., al (2017)

Autonomous Vehicles/Drones uses sensors, actuators and a central computer to assess its surroundings to automate the driving process for assisting the vehicle to drive itself without human involvement. Autonomous vehicle could change the transportation of people from one point to another that could decidedly change the quality of lives. The advances in autonomous vehicle is progessing at a faster pace while fully self-driving vehicles are not yet available, their uses in logistics and supply chain have great promises. Many leading logistics companies are experimenting with self-driving trucks and delivery drones that will negatively impact the labor force that depend its livelihood on delivery of goods. Amazon is hauling cargo in selfdriving trucks developed by Embark (Kolodny, 2019). Self-driving vehicles and drones for package delivery are being investigated by leading online retailers like Amazon and according to Morgan Stanley report (2019) "Labor savings alone would cut costs more than $\$ 70$ billion per year, and productivity would be up 30\% because driverless trucks would run 24/7." Assisted transportation is dependent on deep learning and accelerators (IEEE Top 10 Technology Trends for 2019, 2018). The penetration of autonomous vehicles and drones will continue unabated for the near future with less and less human involvement in the transportation of goods in many manufacturing and service industries.

Advanced Analytics Extensive use of digital technologies is producing huge amount of data doubling every two years in volume. Big data analytics is the tool many companies use to gain value from the seemingly intractable data to gain competitive edge (Cheng et al., 2012, Wang, et al., 2016). Invariably some of these big data is related to logistics and supply chains. Advanced analytics is the method to produce insight from data by utilizing visualization, computer science, mathematics, statistics, behavioral science, simulations, optimizations, or other techniques to help business organizations to make better decisions (Accenture, 2014). Analytics can help organizations monitor targeted measures on continuous basis, identify poor performance before it impacts negatively, and get new insights to come with new products and services through new business processes and innovations (Wang, et al, 2016). Advanced analytics in logistics and supply chains can help an enterprise to mitigate potential hiccup in the supply chain and take corrective actions. As analytics become more common, logistics and supply chain efficiency will be taken for granted and the only areas that need close monitoring are the unexpected events that are outside the control of the operations. Even then, plans should be on hand how to minimize the effect of unforeseen events by designing redundancy as a backup for the operations of logistics and supply chains. The rest of the paper will cover blockchain technology including a summary of Deloitte (2018) survey on the attitude, belief, and advantages of blockchain by more than 1000 business leaders from seven countries. 


\section{Issues in Information Systems}

Volume 20, Issue 2, pp. 47-55, 2019

Blockchain is a distributed transaction ledger with secure application. The information requirements for logistics and supply chains provides a secure supply chain process. The benefits of blockchain transactions among others are transparency, smart contracts, pharmaceutical drug authentications, food logistics, trade and finance with the use of sensing and tracking technologies. Blockchain technology is garnering tremendous interests among organization for its potential benefits in processing transaction without intermediaries and for its robust security. Many practioners and researchers believe blockchain will revolutionize the way we interact and transact over the Internet resulting in efficiencies and high security transactions in contemporary advanced economies (e.g. Swan, 2015, Tapscott, 2016). Decentralization enables privacy, through pseudonymization, and creates a reliable and versatile setting for transaction (Seebacher, 2017). To be able to discuss the impact of these technologies on service systems such as logistics and supply chain, structured literature review on the technology, based entirely on peer-reviewed literature, need to be performed (Seebacher, 2017). For example, blockchain technology requires and enables trust and decentralization in a collaborative transactional environment in its entire network with assurance of data integrity and immutability (Seebacher, 2017). Blockchain technology increases trust while reducing cost of transactions by eliminating the intermediaries. Standardization of protocols will be a thorny issue as many players have not settled on which protocol to adapt. Blockchain adoption is still in its infancy and a survey by Deloitte (2018) was conducted to gauge blockchain technology potential among various companies' executives around the world. Table 1, 2, and 3 depicts the breakdown of countries, job role, functional responsibilities of respondents, attitude toward blockchain, beliefs and potential benefits. The respondents were from four advanced developed countries and two relatively developed countries (Deloitte, 2018).

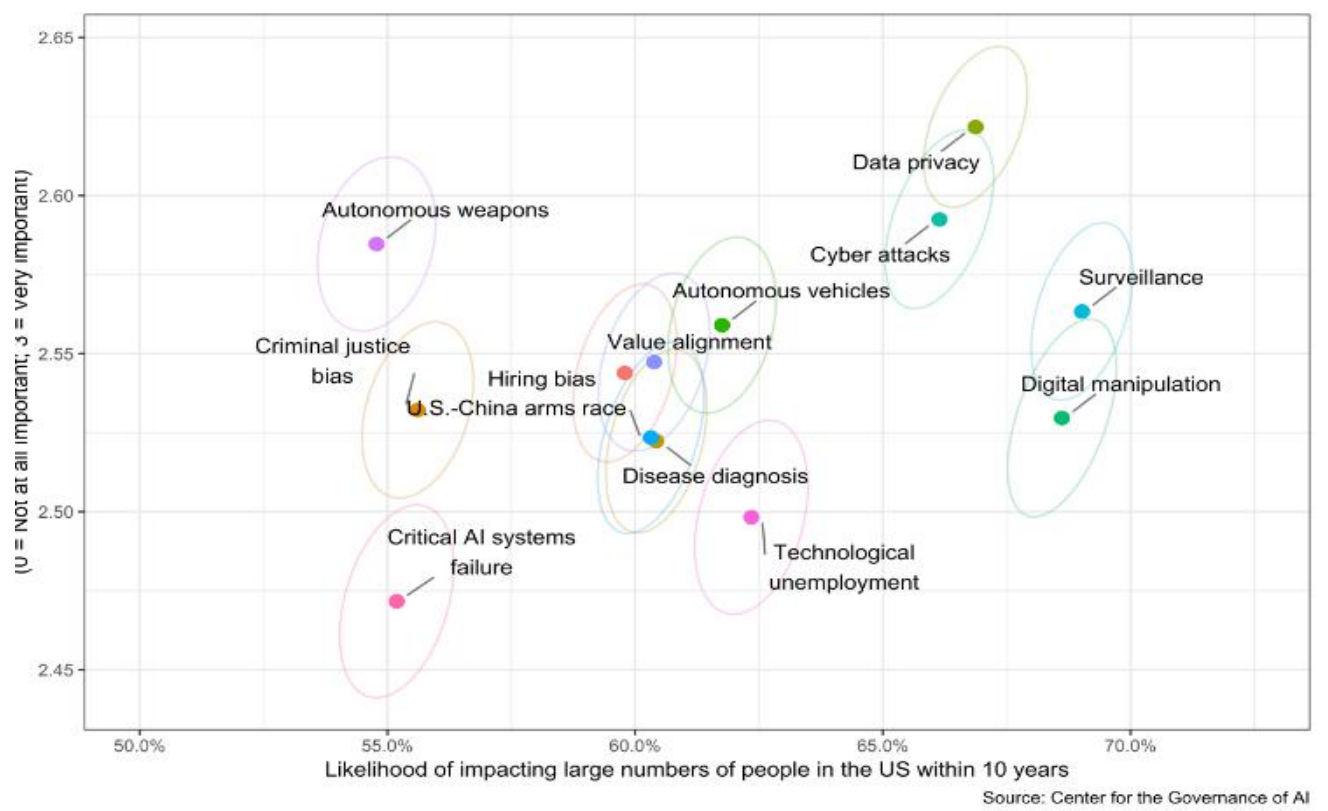

Figure 3. New technology likelihood impact on society *Source: US Public Opinion Report January 2019

As tables 1, 2 and 3 show logistics and supply chain activities are embedded in many of the functional area listed and therefore one can infer blockchain technology can bring great benefits. Most survey respondent attitude of blockchain technology is it can be scalable, will improve the value chain, has compelling business need, and not using it will cause great competitive disadvantage for organization that don't deploy it. Most of the advantages of using blockchain is for transaction speed, create new business model, greater security, and to lower cost of operations efficiency in procurement, contracts, transportation and warehousing functions as seen by many of the respondents. Figure 3 depicts the likelihood of impact of advanced technology such as AI, autonomous vehicles, cyber-attacks on society (Zhang, B and Dafoe A. 2019). Technological surveillance, digital manipulation, cyber attacks, and data privacy were rated as likely impacting society negatively in the next decade. Therefore, more research and regulatory public policies are warranted to mitigate the negative impact on business, individuals and protect democratic form of government. 


\section{Issues in Information Systems \\ Volume 20, Issue 2, pp. 47-55, 2019}

Table 1. BlockChain Survey 2018 (Source Deloitte Global Survey n =1053)

\begin{tabular}{|c|c|c|c|c|}
\hline COUNTRY & $\begin{array}{c}\text { Number of } \\
\text { Respondents }\end{array}$ & Percentage & $\begin{array}{c}\text { Primary Functional } \\
\text { Affiliation of all } \\
\text { Respondents }\end{array}$ & Percentage \\
\hline USA & 284 & $26.97 \%$ & Financial Services & $23 \%$ \\
\hline China & 205 & $19.47 \%$ & Technology/Media/Telecom & $18 \%$ \\
\hline UK & 150 & $14.25 \%$ & Consumers Product Mgt. & $14 \%$ \\
\hline France & 132 & $12.54 \%$ & Health Care & $11 \%$ \\
\hline Canada & 103 & $9.78 \%$ & Other & $10 \%$ \\
\hline Mexico & 103 & $9.78 \%$ & Oil and Gas & $7 \%$ \\
\hline France & 76 & $7.22 \%$ & Automotive & $6 \%$ \\
\hline & & & Life Sciences & $5 \%$ \\
\hline & & & Public Sector & $4 \%$ \\
\hline & & & Food & $3 \%$ \\
\hline
\end{tabular}

Table 2. Current Job/Roles and Functional Area of Respondents

\begin{tabular}{|l|c|l|c|}
\hline \multicolumn{1}{|c|}{ Job Role/Title } & $\begin{array}{c}\text { Percent of } \\
\text { Respondent }\end{array}$ & \multicolumn{1}{|c|}{ Functional Area } & $\begin{array}{c}\text { Percent of } \\
\text { Respondent }\end{array}$ \\
\hline CIO & $26 \%$ & Information Technology & $42 \%$ \\
\hline CEO & $21 \%$ & Sales & $11 \%$ \\
\hline Executive VP & $13 \%$ & Finance & $10 \%$ \\
\hline COO & $9 \%$ & Administration & $10 \%$ \\
\hline President & $8 \%$ & Strategy & $8 \%$ \\
\hline CFO & $6 \%$ & Innovation & $7 \%$ \\
\hline Another C-Suite & $5 \%$ & Other & $4 \%$ \\
\hline Senior Manager & $5 \%$ & Marketing & $4 \%$ \\
\hline Director & $3 \%$ & Procurement & $2 \%$ \\
\hline Chief Strategic Officer & $2 \%$ & Human Resources & $2 \%$ \\
\hline Business Unit Head & $2 \%$ & & \\
\hline
\end{tabular}

Table 3. Survey of Attitude, Beliefs and Advantages of Blockchain

\begin{tabular}{|l|l|l|l|l|l|}
\hline Attitude & $\begin{array}{l}\text { Percent } \\
\text { of } \\
\text { Respon } \\
\text { ders }\end{array}$ & $\begin{array}{l}\text { Beliefs as Disruptor } \\
\text { in Industry }\end{array}$ & $\begin{array}{l}\text { Percent of } \\
\text { Responders }\end{array}$ & $\begin{array}{l}\text { Significant } \\
\text { Advantage of } \\
\text { Blockchain }\end{array}$ & $\begin{array}{l}\text { Percent of } \\
\text { Responders }\end{array}$ \\
\hline Blockchain is scalable & $84 \%$ & Automotive & $73 \%$ & Greater speed & $32 \%$ \\
\hline Addresses Value Chain & $77 \%$ & Oil and Gas & $72 \%$ & $\begin{array}{l}\text { New Business } \\
\text { Model }\end{array}$ & $28 \%$ \\
\hline Compelling Business need & $74 \%$ & $\begin{array}{l}\text { Biotech, Pharma, } \\
\text { Med devices }\end{array}$ & $72 \%$ & Greater Security & $21 \%$ \\
\hline Not using BC will lose advantage & $68 \%$ & Financial Services & $64 \%$ & Lower Cost & $16 \%$ \\
\hline BC is over-hyped & $39 \%$ & $\begin{array}{l}\text { Consumer Prod. } \\
\text { Mfg. }\end{array}$ & $56 \%$ & $\begin{array}{l}\text { No perceived } \\
\text { advantage }\end{array}$ & $2 \%$ \\
\hline & & Health Care & $55 \%$ & Other & $1 \%$ \\
\hline & & $\begin{array}{l}\text { Tech/Media/ } \\
\text { Telecommunication }\end{array}$ & $53 \%$ & & \\
\hline & & Food & $50 \%$ & & \\
\hline & & Other & $50 \%$ & & \\
\hline & & Public Sector & $45 \%$ & & \\
\hline
\end{tabular}




\title{
Issues in Information Systems
}

\author{
Volume 20, Issue 2, pp. 47-55, 2019
}

\section{CONCLUSIONS}

The logistics and supply chain community is constantly looking for new technological innovation that will allow the integration of multimedia contents and develop tools, for example, sensor generated data such as from GPS, RFID and other telematic sources, Intelligent Multimedia Knowledge Application (IMKA), that search knowledge from multimedia contents for predicative analytics. Video, and other similar content media are not easily searchable in their original contents based on a specific data or information as it would to text based and are more difficult to conduct analytics and require clever transformation of data. Future research in this rich field is to incorporate multimedia contents from different sources and use context to improve application performance of logistics and supply chain information exchanges in the network using blockchain technology (Rowe, et. al, 2014). New application on the Internet provides voice to text and text to voice conversion. This medium will enhance in information search tremendously (Turban, e. al., 2004). Contemporary transactions are heavily dependent on being online and is available instantaneously for immediate access. Many online retailers have fast paced delivery service that can deliver orders in few hours. The expectation is blockchain application would even be faster, cheaper and more secure. In the past these efficiencies were gained through advanced enterprise resources planning system that utilize in memory computing and data base to improve supply chain output while minimized operational costs. The interconnected areas that influence logistic and supply chain management such as transportation (land, ocean and air), warehousing, packing and shipment can even gain more efficiencies if blockchain applications are utilized for faster and secure transactions. Therefore, these new technologies are expected to have great impact to new service systems particularly the logistics and supply chains industry as IoT devices are expected to number to more than 20 billion by 2020. (Hung, 2017).

The observations and insights in this paper may serve as the foundation for further discussion and research by both researchers and practioners. New innovation in technologies to enhance supply chain competitiveness and performance by enhancing the overall effectiveness and efficiency of logistics system (Bhandari, 2014). Moreover various innovations in technology have made the task easier and faster besides being less laborious. Selecting the proper technology for logistics and supply chains operations or sub-processes is very critical for business enterprise to gain competitive advantage in today's competitive market (Bhandari, 2014). Furthermore, future research to explore these technologies' applications may provide new insights by conducting theoretical or empirical research.

\section{REFERENCES}

Accenture Global Operations Megatrends Study. (2014). Big Data Analytics in Supply Chain: Hype or Here to Stay? http://www.accenture.com/us-en/Pages/insight-global-operations-megatrends-bigdata-analytics.aspx. Accessed March 20, 2019.

Amazon, https://www.cnbc.com/2019/01/30/amazon-is-hauling-cargo-in-self-driving-trucks-developed-by-embark.html

Benitez, A.B. and Chang, S.F. (2003). "Image Classification Using Multimedia Knowledge Networks," Proceedings of the International Conference on Image Processing, 2003, Barcelona, Spain.

Berman, S.J. (2012). Digital Transformation: Opportunities to Create New Business Models. Strategic Leadership, 40, 1624.

Bhandari, R. (2014). 'Impact of technology on logistics and supply chain management', IOSR Journal of Business and Management, http://www.iosrjournals.org/iosr-jbm/papers/7th-ibrc-volume-2/17.pdf Accessed April 10, 2019.

Chen, H., Chiang, R.H., Storey, V.C., (2012). Business Intelligence and Analytics: From Big Data to Big Impact, MIS Quarterly, 4(36), 1165-1188.

Deloitte Insights (2019). Deloitte's 2019 Global BlockChain Survey (May 2, 2019) Retrieved from https://www2.deloitte.com/content/dam/Deloitte/se/Documents/risk/DI_2019-global-blockchain-survey.pdf 


\section{Issues in Information Systems}

Volume 20, Issue 2, pp. 47-55, 2019

IEEE, (2018). IEEE Computer Society Predicts the Future Tech: Top 10 Technology Trends for 2019, January 27, 2019) Retrieved from https://www.prnewswire.com/news-releases/ieee-computer-society-predicts-the-future-of-tech-top10-technology-trends-for-2019-300767876.html

Fitzgerald, M., Kruschwitz, N., Bonnet, D., \& Welch, M. (2014). Embracing Digital Technology: A new Strategic Imperative. MIT Sloan Management Review, 55, 1-12.

Goudos, O. K, Dallas, P., Chatziefthymiou, S. and Kyriazakos, S (2017). A Survey of IoT Key Enabling and Future Technologies: 5G, Mobile IoT, Semantic Web Applications. Wireless Personal Communication, November 2017, 97(2), 1645-1675.

Hess, T., Matt, C.; Benlian, A., \& Wiesböck, F. (2016). Options for Formulating a Digital transformation Strategy. MIS Quarterly, Executive no. 15.

Hofmann, E. \& Osterwalder, F. (2017). Third-Party Logistics Providers in the digital Age: Towards a New Competitive Arena. Logistics, 1(9).

How Technology is changing the Future of Logistics. (March 5, 2019). Retrieved From https://www.shapiro.com/blog/howtechnology-is-changing-the-future-of-logistics/

Linking the Digital BlockChain to Physical World (March 2, 2019) Retrieved from http://escinst.org/block-chain/

Morgan, S. (201(). Autonomous Vehicle, (April 29, 2019) Retrieved from https://www.morganstanley.com/im/en$\mathrm{ch} /$ intermediary-investor/insights/investment-insights/the-edge-autonomous vehicles.html

Hung, M. (2017). Leading the IoT: Gartner Insights How to Lead in a Connected World.

Ketikidis, P.H., Koh, S.C. L., Dimitriadis, A., Gnasekaran, A, \& Kehajova, M. (2008). The Use of Information Systems for Logistics and Supply Chain Management in South East Europe: Current Status and Future Direction, Omega, no.36, pp.592-599.

Kukier, (1999). http://www.isoc.org/inet99/proceedings/ie/ie_2.htm Accessed on February 13, 2019

Manyika, J., Chui, M., Brown, B., Dobbs, J. B., Roxburgh, C., \& Byers, A. (2011). Big data: The next frontier for innovation, competition, and productivity. Technical report, McKinsey Global Institute.

Materna, (2006), A Proactive Approach to VoIP Security: Understanding VoIP Security Requirements, Threats and Architecture, www.voipshield.com Accessed, August 20, 2006.

McCrea, B. (2018). Where is the Supply Chain Software Headed. Logistic Management, 56.

Morgan, S. (2019). Autonomous Vehicle, (April 29, 2019) Retrieved from https://www.morganstanley.com/im/en$\mathrm{ch} /$ intermediary-investor/insights/investment-insights/the-edge-autonomous vehicles.html

Nevala, K. (2017). The Machine Learning Premier, SAS Best Practices E-Book SAS Institute Inc.

Nevala, K. (2019). Machine Learning for Beginners and Beyond, April 20, 2019 Retrieved from https://www.sas.com/en_us/insights/analytics/machine-learning.html.

Rowe, L. \& Jain, R., (2004). ACM SIGMM Retreat Report on Future Directions in Mulitmedia Research. March 2004, 1-12. 


\section{Issues in Information Systems}

Volume 20, Issue 2, pp. 47-55, 2019

Scambray, J. et al. Hacking Exposed 2 ${ }^{\text {nd }}$ New York: McGraw Hill, 2000 Accessed February 16, 2019.

Schramm, H. J., Czaja, C. N., Dittrich, M., \& Mentschel, M. (2019). Current Advancements of and Future Developments for Fourth Party Logistics in a Digital Future. Logistics, 2-17.

Seebacher, S., (2017). Blockchain Technology as an Enabler of Service Systems: A Structured Literature Review Conference Paper in Lecture Notes in Business Information Processing · April 2017.

Simon, A., Singh Deo, M., Venkatesan, S. \& Ramesh, B. (2016). An Overview of Machine Learning and its Applications. International Journal of Electrical Sciences \& Engineering, 1(1), 22-24.

State of IT, 2019, (February 14, 2019) Retrieved from https://www.spiceworks.com/marketing/state-of-it/report/future-tech/

Swan, M. (2015). Blockchain: Blueprint for a New Economy. O'Reilly Media, Inc.

Tapscott, D., \& Tapscott, A. (2016). Blockchain Revolution. Penguine Random House, New York.

Turban, E., King, D., Viehland, D. \& Lee J. (2006). Electronic Commerce: A Managerial Perspective. Prentice Hall.

Vahdani, B, Behzadi, Sadigh, S. \& Mousavi, M. (2015). An Artificial Intelligence Model Based on LS-SVM for Third party Logistics Provider Selection. International Journal of Industrial Mathematics, 7(4), Article ID IJIM-00534.

Waller, M.A., \& Fawcett, S.E. (2013). Data Science, Predictive Analytics, and Big Data: A Revolution that Will Transform Supply Chain Design and Management. Journal of Business Logistics, 2(34), 77-84.

Wang, G., Gunasekaran, A., Ngai, E., \& Papadopoulos, T., (2016) Big data analytics in logistics and supply chain management: Certain investigations for research and applications. International Journal of Production Economics, $176,98-110$.

Whiston, G. M. III (2018). Artificial Intelligence. Salem Press Encyclopedia of Science.

Zach, E. (2018). Enhance efficiency by automating IT services. Computer Weekly, July 208, 19.

Zhang, B. \& Dafoe,,A “Artificial Intelligence: American Attitudes and Trends,” (January 2019) Retrieved from https://governanceai.github.io/US-Public-Opinion-Report-Jan-2019/public-opinion-on-aigovernance.html\#fig:airisksus 